\title{
Self-emulsifying therapeutic system: a potential approach for delivery of lipophilic drugs
}

\author{
Jyoti Wadhwa*, Anroop Nair, Rachna Kumria \\ M.M. College of Pharmacy, M.M. University, Mullana, Ambala, Haryana, India
}

\begin{abstract}
Self-emulsifying therapeutic system (SETs) provide an effective and intelligent solution to the various issues related to the formulation of hydrophobic drugs with limited solubility in gastrointestinal fluid. Although the potential utility of SETs is well known, only in recent years has a mechanistic understanding of the impact of these systems on drug disposition emerged. These in situ emulsion-forming systems have a high stability when incorporated in various dosage forms. SETs are being looked upon as systems which can overcome the problems associated with delivery of poorly water soluble drugs. An in-depth knowledge about lipids and surfactants that can contribute to these systems, criterion for their selection and the proportion in which they can be used, represent some crucial factors determining the in vivo performance of these systems. This article presents a comprehensive account of various types of self-emulsifying formulations with emphasis on their composition and examples of currently marketed preparations.
\end{abstract}

Uniterms: Lipid based formulations. Self-emulsifying therapeutic system. Self-emulsification.

O sistema terapêutico auto-emulsionante (SETs) fornece solução eficaz e inteligente para os vários problemas relativos à formulação de fármacos hidrofóbicos com solubilidade limitada no fluido gastrintestinal. Embora a utilidade potencial dos SETs seja bem conhecida, só recentemente se compreendeu, mecanisticamente,o impacto desses sistemas na disposição de fármacos. Estes sistemas de formação de emulsão in situ têm alta estabilidade, quando incorporados em várias formas de dosagem. Os SETs têm sido considerados como sistemas que podem resolver problemas associados à liberação de fármacos pouco solúveis em água. O conhecimento profundo dos lipídios e tensoativos que podem ser utilizados para estes sistemas e o critério para a sua seleção e proporção na qual eles são utilizados são alguns dos fatores cruciais que determinam o desempenho do sistema in vivo. Este artigo apresenta o relato abrangente de vários tipos de formulações auto-emulsificantes, com ênfase em sua composição e exemplos das preparações que são correntemente comercializadas.

Unitermos: Formulações baseadas em lipídio. Sistema terapêutico auto-emulsificante. Autoemulsificação.

\section{INTRODUCTION}

In the last decade, one of the major evolutions in the areas of pharmaceutics and drug delivery was the recognition of benefits of formulating low water soluble actives as lipid based formulations, a process frequently referred to as a self-emulsifying therapeutic system. Low aqueous soluble compounds include a significant and increasing proportion of drug candidates, often viewed as high-risk drug candidates (Chong-Kook, Park, 2004; Giliyar et al., 2006; Fahr and Liu, 2007; Stegemann et al., 2007;

*Correspondence: Jyoti Wadhwa. M. M. College of Pharmacy, M. M. University, Mullana, Ambala, Haryana - India. E-mail: jyotiwadhwa29@gmail.com
Krishnaiah, 2010). The challenge lies in formulating these poorly-water soluble drug candidates. Extensive research is being carried out by formulation/drug delivery scientists to develop strategies to augment the solubility and delivery of biopharmaceutical classification system (BCS) class II and IV molecules (Benet et al., 2008; Dressman et al., 2001). Some approaches exploited to enhance drug solubility include preparation of solid dispersions (Sethia, Squillante, 2003; Leuner, Dressman, 2004), formulation of soft gelatin capsules (Gullapalli, 2010), cyclodextrin inclusion complexes (Stella, Qanren, 2008; Davis, Brewster, 2004), melt extrusion (Breitenbach, 2002), emulsions (Bittner, Mountfield, 2002), micro-emulsions 
(Kawakami et al., 2002; Pouton, 2000), liposomes (Fenske et al., 2008; Malam et al., 2009) and micellar systems (Mohanty et al.,2010), in addition to the traditional methods such as use of co-solvents or salt/pro-drug formation. However, the lipid based formulation approach is considered a relatively newer strategy.

The value, utility and commercial viability of this approach for compounds with a low aqueous solubility has been demonstrated in recent years (Liversidge et al., 1995; Muller, 2001; Merisko-Liversidge et al., 2003; Pathak et al., 2005; Keck, Muller, 2006; Overhoff et al. 2007; Pu et al., 2009; Timpe, 2010). In addition, this approach has received significant attention, as reflected in the number of publications and reviews that have appeared recently (Hauss, 2007; Tang et al., 2008). A number of informative reviews have been published relating to biopharmaceutical aspects, strategies for formulation of self-emulsifying systems and efforts to understand their mechanisms of action (Humberstone, Charman, 1997; Constantinides, 1995; Pouton, 1997; Gershanik, Benita, 2000). In practice, 'lipid' formulations are a diverse group of formulations which have a wide range of properties.

The unique properties of lipids and their proven ability to formulate poorly-water soluble molecules may have a remarkable impact on enhancing bioavailability of drugs, eliminating food effects, allowing for dose escalation and thereby improving efficacy and safety. The present review is focused on the efforts that have been made in the field of self-emulsifying formulations for poorly water soluble drugs. Current developments in the design and development of self-micro emulsifying and self-nano emulsifying formulations have also been highlighted.

\section{NEED FOR LIPID BASED FORMULATIONS}

During the last two decades, considerable efforts have been made in identifying biological targets of drug candidates. Also a number of lead molecules have been generated through combinatorial chemistry. With the availability of vast chemical libraries of new chemical entities, focus was set on designing molecules having high affinity binding constants for their biological targets. These biological properties combined with appropriate physical and chemical properties could revolutionise drug development. However, poor aqueous solubility of drugs continues to remain a concern (Stegemann et al., 2007; Alsenz, Kansy, 2007; Li, Zhao, 2007).

Generally, for a drug to show a high affinity and specificity for binding to molecular targets some degree of hydrophobic interactions is required where this hydrophobic interaction is likely to cause solubility constraints.
While over $40 \%$ of molecules derived from combinatorial chemistry possess low aqueous solubility (Amidon, 2006; Lipinski, 2002; Lipinski, 2001) this percentage can reach $\sim 90 \%$ if the compound selection is not done cautiously. Only one out of approximately 5,000-10,000 new chemical entities (NCE) is successful as a drug candidate when there are no feasible means to deal with solubility issues. With an increasing number of poorly-water soluble NCE, it is necessary to evaluate and test these molecules to realize their genuine potential. The ability to use a drug delivery enabling technology for poorly-water soluble compounds could potentially have a tremendous impact on moving compounds successfully from discovery, through development and to the patient. In this context, application of lipid based formulations could be used for low aqueous soluble compounds and may ensure the success of the NCE.

"Lipid-based drug delivery systems" cover a wide array of formulation types, from oil solutions, emulsion and dry emulsions to Self-Emulsifying formulations (SEFs) as well as micellar systems. The absorption enhancing properties of lipid-based drug delivery syste$\mathrm{ms}$ are most often attributed to the ability of the vehicles to keep the API in solution in the gastrointestinal (GI) tract, thereby omitting the dissolution step. The absorption of the API will depend upon trafficking between different colloidal phases generated in the intestine. Lipid based drug delivery systems, and in particular self-emulsifying therapeutic systems (SETs), show great potential for enhancing oral bioavailability but have not been broadly applied, largely due to lack of general formulation guidance. To help understand how formulation design influences physicochemical emulsion properties and associated function in the gastrointestinal environment, a number of studies carried out on self-emulsifying formulations have been discussed in the sections that follow.

\section{SELF-EMULSIFYING THERAPEUTIC SYSTEM (SETS)}

SETs are pre-concentrates or anhydrous forms of emulsions. These systems are an anhydrous isotropic mixture of oils, surfactant(s) and drug, which when introduced into the aqueous phase under gentle agitation, spontaneously form o/w emulsion (droplet size between 100 and $300 \mathrm{~nm}$ ) while self-micro emulsifying formulations (SMEFs) form transparent micro-emulsions with a droplet size of less than $50 \mathrm{~nm}$. Formulations based on SETs contain co-emulsifier or co-surfactant and/or solubilizer in order to facilitate emulsification and improve 
drug incorporation in SETs. Within the human body, the required agitation is provided by digestive motility of the GI tract (GIT).

SETs are usually formulated as simple emulsions or self-emulsifying formulations (SEFs) making use of surfactants with an HLB value of less than 12. Selfmicro-emulsifying formulations (SMEFs) and self-nano emulsifying formulations (SNEFs), on the other hand, are formulated using surfactants with an HLB value of more than 12. These formulations possess high stability and improved dissolution due to enhanced surface area upon dispersion. The comparative features of reported systems are illustrated in Figure 1.

\section{Self-emulsification process}

Self-emulsification takes place when the entropy change favours dispersion and is greater than the energy required to increase the surface area of the dispersion (Reiss, 1975). The free energy of a conventional emulsion formulation is a function of the energy required to create a new surface between the oil and water phases. The two phases of the emulsion tend to separate with time and reduce the interfacial area, and thus the free energy of the systems. The conventional emulsifying agents stabilize emulsions by forming a monolayer around the emulsion droplets, reducing the interfacial energy and forming a barrier to coalescence.

On the other hand, emulsification occurs spontaneously with SEFs because the free energy required to form the emulsion is low (Constantinides, 1995). For emulsification to occur, the interfacial structure must not show any resistance against surface shearing. The ease of emulsification is probably related to the ease of water penetration into the various liquid crystals or gel phases formed on the surface of the droplet (Groves et al., 1974; Wakerly et al., 1986; Rang, Miller, 1999). The interface between the oil and aqueous continuous phase is formed upon addition of a binary mixture consisting of oil and non-ionic surfactant in water. This is followed by the solubilisation of water within the oil phase as a result of aqueous penetration through the interface. This will continue until the solubilisation limit is reached. Further, aqueous penetration will lead to formation of the dispersed liquid crystals phase. Anything that is in close proximity with the interface will be in the form of liquid crystals and the actual amount of the liquid crystal will depend upon the concentration of surfactant in the binary mixture. Thus, following gentle agitation of the self-emulsifying system, water will rapidly penetrate into the aqueous cores and lead to interface disruption and droplet formation.

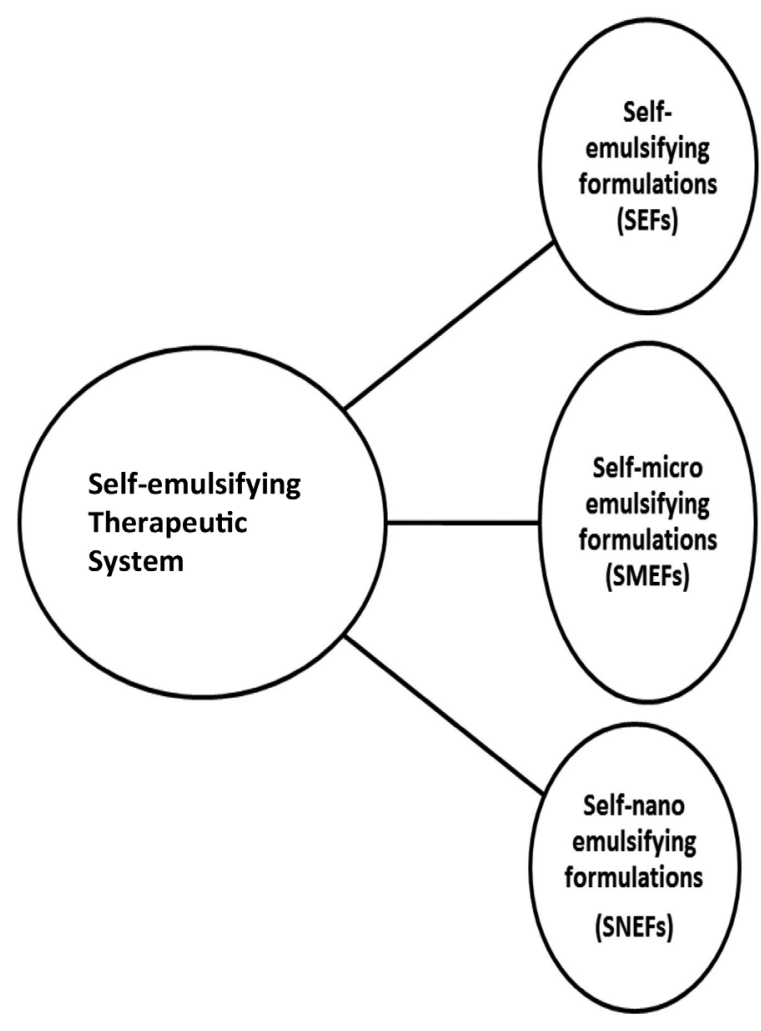

-Oil droplet size $200 \mathrm{~nm}-5 \mu \mathrm{m}$. -Appearance of dispersion is turbid.

-Formulations formed using surfactants of HLB $<12$. -Thermodynamically stable in physiological conditions. -Development may require characterization of ternary phase diagram.

-Oil droplet size100-250 nm. - Appearance of dispersion is optically clear to translucent. - Formulations formed using surfactants of HLB > 12 . -Thermodynamically stable in physiological conditions. -Development may require characterization of pseudo ternary phase diagram.

-Oil droplet size $<100 \mathrm{~nm}$ -Appearance of dispersion is optically clear. - Formulations formed using surfactants of HLB $>12$. -No phase separation during storage. -Development may require characterization of pseudo ternary phase diagram.

FIGURE 1. Features of different self-emulsifying formulations. 


\section{Formulation considerations and potential components}

A thorough understanding of the spontaneous emulsification process, the physiochemical and biological properties of components used for fabrication of SETs, is essential for formulation of effective SETs. Factors influencing the phenomenon of self-emulsification include:

- The physiological nature and concentration of oily phase, surfactant, co-emulsifier or co-surfactant and solubilizer;

- The ratio of each component, especially oil to surfactant ratio;

- The temperature and $\mathrm{pH}$ of the aqueous phase where emulsification would occur;

- Physicochemical properties of the drug, such as hydrophilicity/ lipophilicity, pKa and polarity.

Acceptability of SEFs components for the desired route of administration is important while formulating SEFs. Only specific pharmaceutical excipient combinations lead to efficient self-emulsifying systems (Charman et al., 1992; Shah et al., 1994; Hauss et al., 1998; Karim et al., 1994). The components of SEFs which need considering are discussed below.

\section{Oil phase}

Oil phase has great importance while formulating SEFs, as the physicochemical properties of the oil (e.g. molecular volume, polarity and viscosity) significantly affect the spontaneity of the emulsification process, the droplet size of emulsion $(\mathrm{o} / \mathrm{w})$, drug solubility and biological fate of both the emulsion and drug. Oil phase represents one of the most important excipients in SEFs as it solubilizes the lipophilic drug, facilitates self-emulsification, and increases the fraction of lipophilic drug transported through the intestinal lymphatic system. This in turn increases the absorption from the GIT. However, the absorption is dependent upon the molecular nature of the triglyceride (Gershanik and Benita, 2000; Charman, 1991; Holm et al., 2002).

Oils with medium hydrocarbon chain length (medium chain triglycerides) and oils with short chains (or low molecular weight), such as medium chain triglycerides and fatty acid esters (e.g. ethyl oleate), are easy to emulsify as compared with long chain triglycerides (Antron, Vandamme, 2009). Novel semi-synthetic medium chain derivatives, which can be defined as amphiphilic compounds with surfactant properties, are progressively replacing the regular medium chain triglyceride oils in the SEFs (Constantinides, 1995; Karim et al., 1994).
It is difficult for a single oil component to have optimum properties with respect to emulsification and drug delivery. In certain cases, using a mixture of oils can also be used to attain optimum properties of the oily phase. Vitamin E (D- $\alpha$ - tocopherol) is increasingly being used as an oily phase in SEFs owing to its ability to solubilize drugs that are difficult to solubilize using conventional oil components, for example paclitaxel, itroconazole and saquinavir (Constantinides et al., 2004).

\section{Surfactants}

The choice of surfactant is critical for the formulation of SEFs. The properties of surfactants such as HLB value, cloud point, viscosity and affinity for oil phase, all have a strong influence on the emulsification process and droplet size. There is a direct relationship between the droplet size and concentration of surfactant being used. Increasing the surfactant concentration may lead to droplets with smaller mean droplet size. This could be explained by the stabilization of the oil droplets as a result of the localization of the surfactant molecules at the oil-water interface (Karim et al., 1994). On the other hand, in a few cases the mean droplet size was found to increase with greater surfactant concentrations (Georgakopoulos et al., 1992). This phenomenon could be attributed to the interfacial disruption elicited by enhanced water penetration into the oil droplets mediated by increased surfactant concentration, leading to ejection of oil droplets into the aqueous phase.

Surfactants used in these formulations improve the bioavailability of the drug. This can be attributed to different mechanisms including improved drug dissolution, increased intestinal epithelial permeability, increased tight junction permeability and inhibited P-glycoprotein drug efflux. However, a large quantity of surfactant may cause moderate reversible changes in intestinal wall permeability or may irritate the gastrointestinal tract. However, formulation effect and effect of surfactant concentration on GIT mucosa should ideally be investigated in each case.

Several compounds exhibiting surfactant properties may be employed for the formulation of self-emulsifying systems. However, the list of such surfactants is limited. The most widely recommended non-ionic surfactants such as polysorbates (e.g., Tween ${ }^{\circledR} 80$ ) and polyethylene glycol derivatives (e.g., Cremophor ${ }^{\circledR}$ EL) possess HLB in the 2 to 18 range. These may be used in combination with lipid excipients to promote self-emulsification or micro-emulsification (Gibson, 2007). High HLB value and hydrophilicity are desirable characteristics of the surfactants for an immediate formation of $\mathrm{o} / \mathrm{w}$ droplets and rapid spreading of the formulation in the aqueous environment. The acceptable 
amount of these otherwise low toxicity surfactants that can be used in the formulation of dosage forms is limited. This is primarily due to the tendency of these surfactants to cause brittleness in hard and soft gelatin capsule shells due to their dehydrating effects (at high concentrations).

Emulsifiers of natural origin are preferred in these formulations as they are considered safer than synthetic surfactants. Galactolipids, the polar lipids commonly found in the chloroplast membranes of green plants have been used as a surfactant in the formulation of cyclosporine (Odeberg et al., 2003). However, surfactants of natural origin usually have a limited self-emulsification capacity (Gursoy et al., 2004).

Digestion of surfactants has been found to have an impact on the performance of SEFs. This is because the digestion of surfactant can change the solubilisation environment of the drug, which in-turn can causes precipitation of the poorly water-soluble drugs (Cui et al., 2009; Fernandez et al., 2009). In addition, very little is known about the formation of degradation products of surfactants and their interactions with fatty acids, endogenous lipids (bile salts), phospholipids and dietary lipids. These factors may play a significant role in maintaining the solubility of poorly water-soluble drug in solution and the requisite building of mixed micelles might be compromised (Fernandez et al., 2009).

Taking into account all these findings makes it apparent that knowledge of possible inhibitory effects of non-ionic surfactants on triglyceride digestion is crucial for the rational development of SEFs. Moreover, the susceptibility of the surfactants themselves to degradation by pancreatic enzymes is a crucial factor to be considered during formulation development.

\section{Co-solvents}

Usually an effective SEF requires a high concentration of surfactant. Accordingly, co-solvents such as ethanol, propylene glycol and polyethylene glycol are required to facilitate the dissolution of large quantities of hydrophilic surfactant. These co-solvents sometimes play the role of the cosurfactant in the microemulsion system. On the other hand, alcohol and other volatile co-solvents have the drawback of evaporating into the shell of soft or hard gelatin capsules, leading to precipitation of the drug.

\section{Aqueous phase}

The droplet size and stability of $\mathrm{W} / \mathrm{O}$ emulsion is influenced by the nature of aqueous phase where SETs is designed to be introduced. Hence, the $\mathrm{pH}$ and ionic content of aqueous phase is of prime importance when designing SETs. The physiological milieu has a diverse $\mathrm{pH}$ range varying from a $\mathrm{pH}$ of 1.2 (stomach) to around 7.4 (blood and intestine). In addition, the presence of various ions in the physiological milieu can also have a considerable effect on the properties of emulsions generated from SETs. The presence of electrolytes has been found to have an impact on emulsion characteristics such as droplet size and physical stability (Morais et al., 2006). Hence, it is advisable to evaluate the self-emulsification of the SETs and the characteristics of resultant w/o emulsion in aqueous phases with varying $\mathrm{pH}$ and electrolyte concentration (depending upon the type of application). In addition to plain water, ringer's solution, simulated gastric fluid $(\mathrm{pH}$ 1.2), simulated intestinal fluid ( $\mathrm{pH}$ 6.8) and phosphate buffer saline can be used as aqueous phase to evaluate spontaneous emulsification of SETs. In one study, $\mathrm{pH}$ of the aqueous phase was found to have a dramatic influence on the phase behavior of the SNEFs, especially when a drug with $\mathrm{pH}$-dependent solubility is loaded in the system (Date, Nagarsenker, 2007).

\section{Drug}

It is important to bear in mind that the therapeutic agent of interest can also have a significant impact on the various aspects of SETs, such as phase behavior and emulsion droplet size. Physiochemical properties of the drug, such as $\log \mathrm{P}, \mathrm{pKa}$, molecular structure and weight, presence of ionizable groups and their quantity all have considerable impact on the performance of SETs. Date and Nagarsenker (2007) observed that the incorporation of the drug (Cefpodoxime proxetil) in the SNEFs reduced the nano emulsification region when the aqueous phase was water. However, as $\mathrm{pH}$ of aqueous phase was changed to 1.2 , the nano-emulsification region increased due to $\mathrm{pH}$-dependent solubility of the drug. Furthermore, it was also observed that incorporation of drug into the SNEFs could increase the nanoemulsion droplet size as compared with SNEFs without drug. Similar observations have been noted by Wang et al. (2009) in the case of SNEFs of flurbiprofen. The droplet size of the nano-emulsion was found to rise with increasing amounts of drug in the SNEFs. Drugs showing surface activity, such as sodium salicylate, ascorbic acid and tricyclic amines, may show different behavior with an increasing concentration in SNEFs.

In another study, the self nanoemulsification region was found to enlarge upon increasing the concentration of the drug simvastatin from 10 to $40 \mathrm{mg}$ in the SNEFs. These results suggested that simvastatin may have mild cosurfactant activity at the oil and water interface due to 
its amphiphilic nature (Dixit, Nagarsenker, 2008). Owing to the acidic nature of self-nanoemulsifying systems, simvastatin prodrug may get converted to simvastatin acid. In-silico studies suggested that a high number of rotatable bonds in simvastatin acid may interact with the surfactant and co-surfactant molecules. Flexibility of a molecule helps in forming a close-packed stable interfacial film that yields highly stable nano-emulsions. The results imply that the properties and amount of the drug have a considerable influence on various aspects of SETs.

\section{ROLE OF SELF-EMULSIFYING THERAPEUTIC SYSTEMS IN DRUG DELIVERY}

Once the formulator succeeds in addressing the challenges of drug solubility and absorption, the next major challenge they face is the delivery of drug in an acceptable dosage form. It is an undisputed fact that oral dosage forms are the most preferred. Further, lipid formulations offer versatility for oral dosage forms as these can be formulated into various formulation such as solutions, semi-solids and solid forms. Traditionally, lipid-based formulations are prepared as liquids and administered orally in either soft or hard gelatin capsules. However, there may several limitations associated to the delivery of SEFs in hard and soft gelatin capsules. These include drug incompatibility, instability, drug leakage, precipitation and capsule ageing. An alternative method is conversion into a powder form which can then be used for formulating tablets, capsules, etc. (Nazzal et al., 2002; Newton et al., 2007).

Many lipophilic drugs, e.g., coenzyme Q10, diclofenac, loratadine and cyclosporin A, vitamin E, itroconazole etc. have been formulated in SETs. The different drugs, their formulations and the excipients used in self-emulsifying therapeutic system are summarized in Table I.

\section{Self-emulsifying tablets (SE tablets)}

Incorporation of lipid formulation into a solid dosage form combines the advantages of lipid-based drug delivery systems with those of solid dosage forms. Attama (2003) formulated a solid self-emulsifying formulation using goat fat and tween for the delivery of diclofenac. Fatty material was melted and mixed with surfactant and the drug incorporated into this mixture. This wet mass was poured into plastic molds and cooled to form a tablet. During the processing of this formulation it was observed that agitation during fabrication of tablets reduced the liquification time, resulting in faster emulsification. These results demonstrated that different formulation ratios possess varying dissolution profiles at constant speed/agitation, and the optimized formulation showed good release profiles with acceptable tablet properties.

Nazzal and Khan (2006), evaluated the effect of some parameters (colloidal silicates-X1, magnesium stearate mixing time $\mathrm{X} 2$, and compression force $\mathrm{X} 3$ ) on coenzyme Q10 (CoQ10) dissolution from tablets of eutectic-based SMEFs. The optimized conditions (X1 $=1.06 \%, \mathrm{X} 2=2 \mathrm{~min}, \mathrm{X} 3=1670 \mathrm{~kg}$ ) were achieved by a face centred cubic design.

In order to significantly reduce the amount of solidifying excipients required for transformation of SEFs into solid dosage forms, gelled SEFs have been developed by Patil (2004). In this study, colloidal silicon dioxide (Aerosil 200) was selected as a gelling agent for the oil-based systems. Colloidal silicon dioxide served a dual purpose: (i) - reducing the amount of solidifying excipients required; and (ii) aiding in reducing drug release.

In a clinical study, it was found that SE tablets may be of use in reducing adverse effects (Schwarz, 2003). The incorporation of indomethacin (or other hydrophobic NSAIDs) in SE tablets was found to increase the penetration efficacy of the drug through the GI mucosal membranes, potentially reducing GI bleeding. The SEF in this study composed of glycerol monolaurate and Tyloxapol TM (a copolymer of alkyl phenol and formaldehyde). The tablets consistently maintained a higher active ingredient concentration in blood plasma over the same time period compared with a non-emulsifying tablet.

\section{Self-emulsifying powder formulation (SE powder formulation)}

Arida et al. (2007) formulated an SE powder formulation in order to enhance the dissolution and absorption of the poorly water-soluble drug griseofulvin. Capmul GMO50 , poloxamer and myvacet were used as surfactants and co-surfactants. A significant enhancement in dissolution (without ultra-micronisation) and bioavailability of griseofulvin was observed.

Balakrishnan et al. (2009) developed a novel solid SEF of dexibuprofen using spray drying. Aerosil 200 was used as an inert solid carrier. Both in-vitro and in-vivo studies were carried out. The optimization of the SEF composition was carried out by assessing solubility, preparation of phase diagram, particle size analysis, drug release studies etc. The study showed that Labrafil M 1944 CS, Labrafil M 2125, Labrasol, Capryol 90 and Lauroglycol FCC could enhance the solubility of CoQ10 and provide the desired drug loading. 


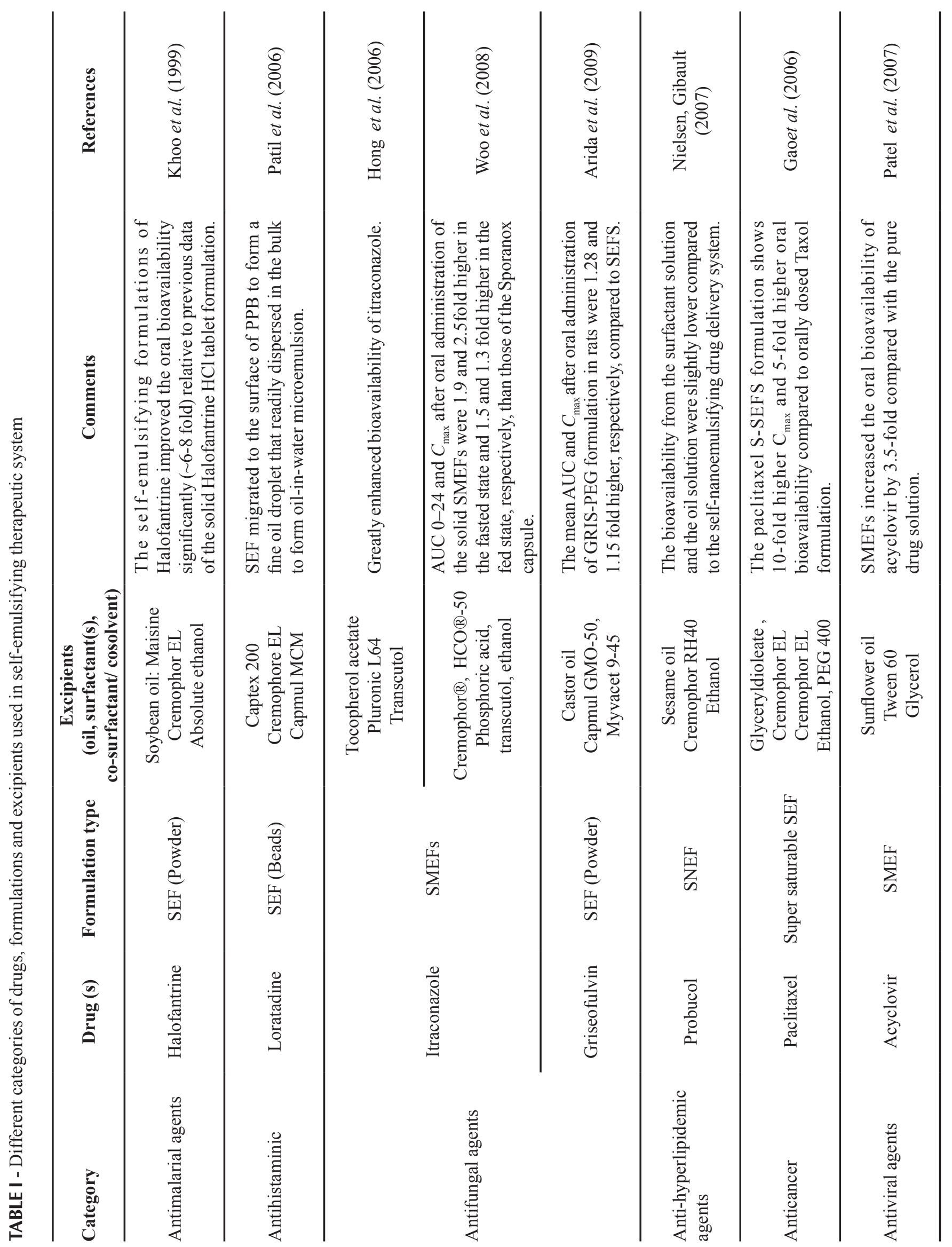




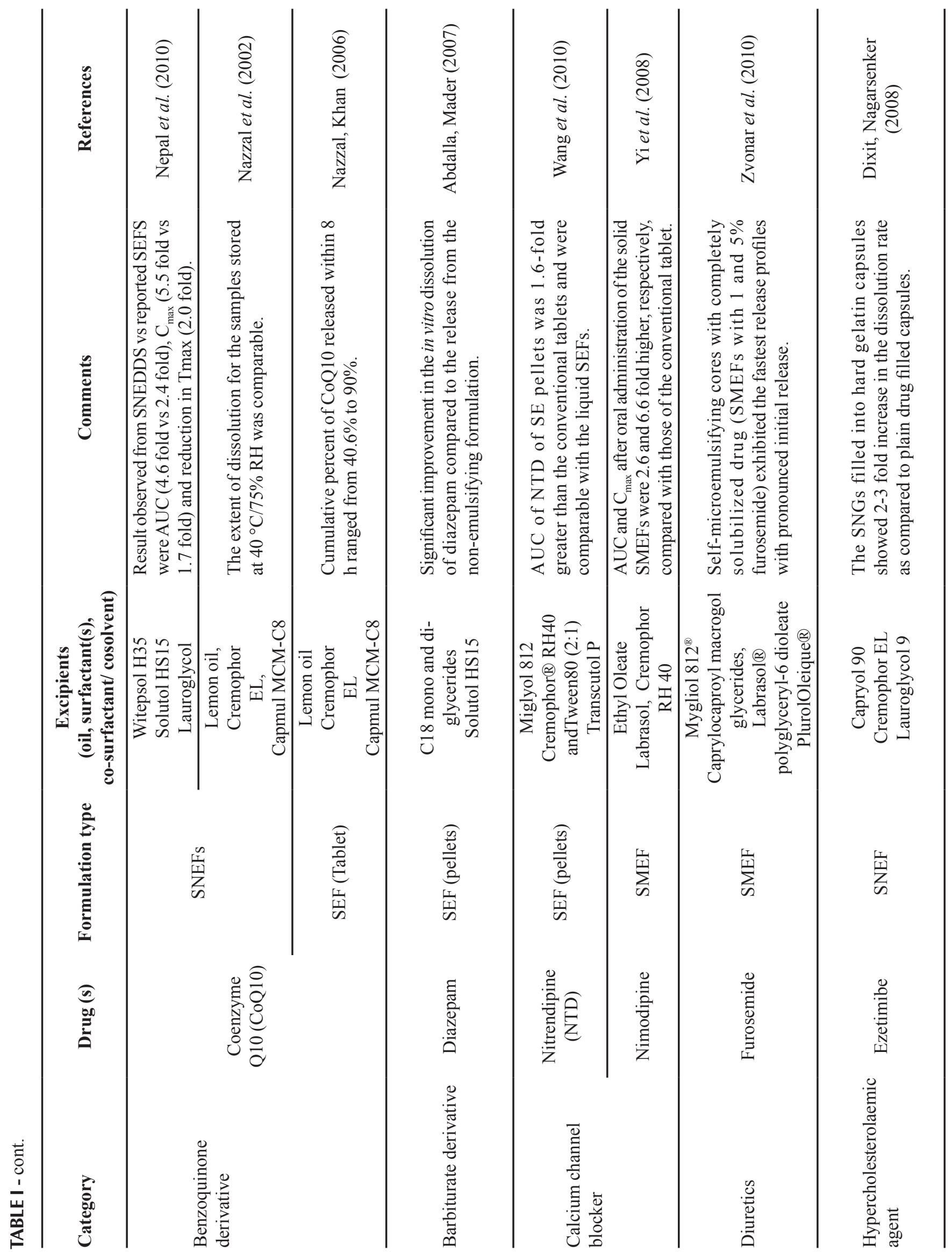




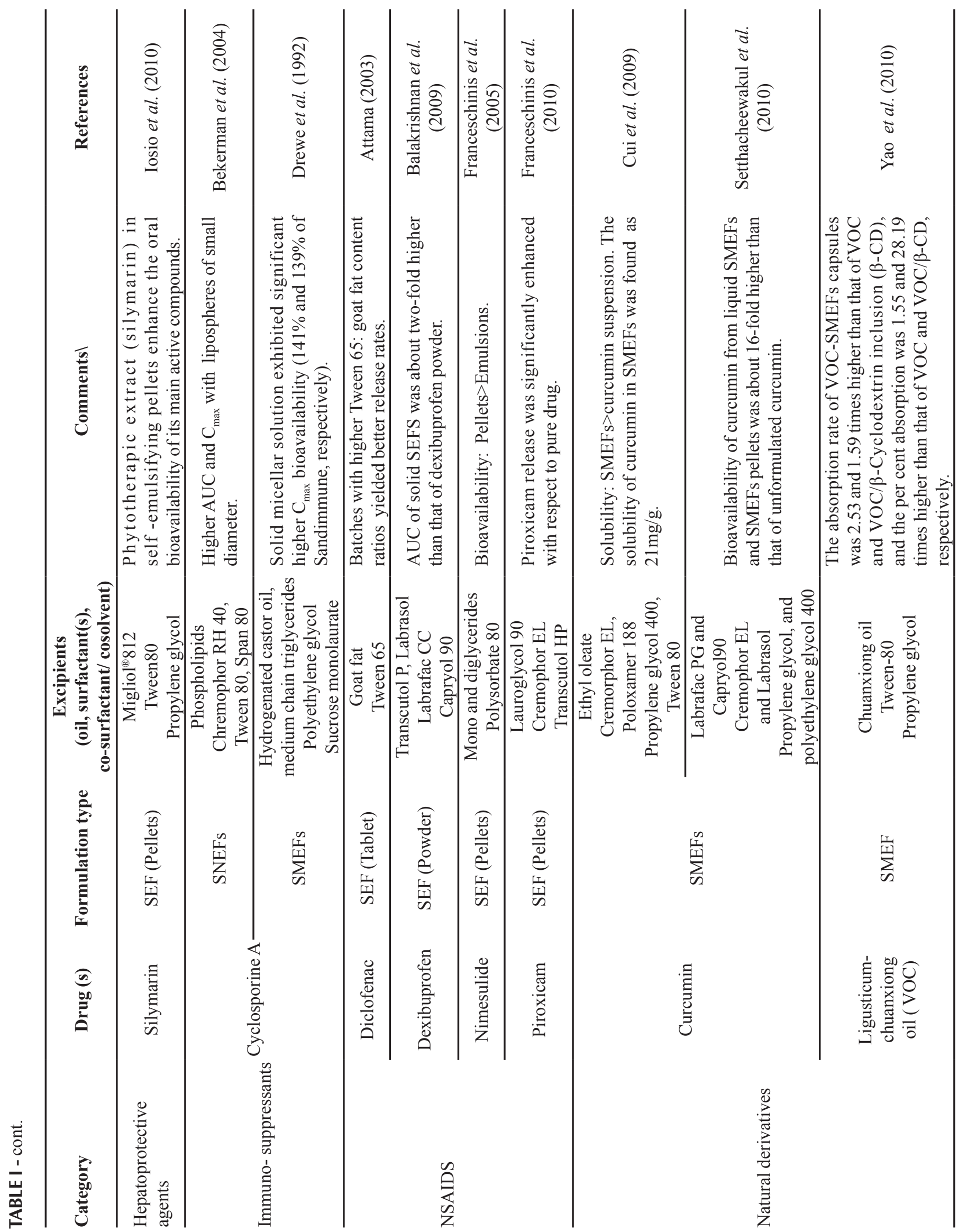









\section{Self-emulsifying pellets (SE pellets)}

Oral pellets are known to overcome the poor and variable GIT absorption of drugs and have shown the ability to reduce or eliminate the influence of food on bioavailability. Thus, it appears highly appealing to combine the advantages of pellets with those of SETs by formulating SE pellets. Kang et al. (2004) as part of their study to develop a self-emulsifying drug delivery system, have reported considerable differences in the solubility of simvastatin in a range of surfactants. The authors suggest that the properties of surfactants need to be considered when selecting them for the formulation of SE pellets.

Franceschinis et al. (2005) developed a new method for preparing self-emulsifying pellets by wet granulation consisting of a binder solution containing an oil (mono and diglycerides), polysorbate 80 and nimesulide as a model drug. The oil surfactant mixture was added to water to obtain binder solution. The prepared binder solutions were sprayed onto the granules (prepared from microcrystalline cellulose and lactose) to give pellets. In vivo studies indicated significantly higher bioavailability with the prepared pellets in comparison to the corresponding emulsions.

Tuleu (2004) conducted a comparative bioavailability study of progesterone from SE pellet formulation, SE solution, capsule and an aqueous suspension in dogs. Complete drug release was seen within $30 \mathrm{~min}$ of capsule administration and within 5 min of administration of the self-emulsifying system. However, in the case of aqueous suspension the drug release was very low $(\sim 50 \%$ of the dose in $60 \mathrm{~min}$ ). Plasma drug concentration was significantly higher when the drug was orally administered from self-emulsifying pellets and self-emulsifying solution when compared to aqueous suspension at the same dose.

Abdalla and Mader (2007) prepared three selfemulsifying pellet formulations by melting cithrol GMS (mono and diglycerides) and solutol HS 15. To this molten blend, the drug (diazepam) and dry microcrystalline cellulose (MCC) were added to obtain a suitable mass for extrusion. A dye was incorporated for assessment of self-emulsification and spin probe was added to assess the release kinetics and microenvironment of pellets. The results from the release study, with higher load of diazepam and lower volume of the dissolution media, indicated that the formulation was able to create and maintain a state of supersaturation for the poorly water-soluble diazepam. Nearly $90 \%$ of the drug was released within an hour while only $55 \%$ was released from the GMS/MCC pellets.

Wang et al. (2010) demonstrated that the extrusion/ spheronization technique is a large-scale production method for preparing solid SE pellets from the liquid SEF to improve oral absorption. SE pellets of a hydrophobic drug (nitrendipine) were prepared. Formulation stability and solubilisation capacity were noted. The system was optimized on the basis of equilibrium solubility, pseudoternary phase diagram and supersaturation studies. The liquid SEFs were solidified using adsorbents (porous silicon dioxide), MCC and lactose to form fine flowable powder. Crospovidone was added to the formulation. The AUC of nitrendipine from the SE pellets was two-fold greater than the conventional tablets and was comparable with the liquid SEFs.

\section{Controlled release self-emulsifying pellets}

Serratoni and Newton (2007) observed that the release of methyl paraben (MP) and propyl parabens (PP) from pellet formulations could be controlled by incorporating them into self-emulsifying systems containing water soluble plasticiser and talc. Oil and surfactant were mixed and added to the damp mass of MCC and lactose monohydrate. Extrusion spheronization of the wet mass was carried out. The pellets obtained were initially coated with ethyl cellulose and subsequently with an aqueous solution of hydroxy propylmethyl cellulose in a fluid bed coater. Results obtained from the in vitro study revealed that the presence of self-emulsifying system enhanced drug release of MP and PP while the film coating considerably reduced the drug release from pellets.

Iosio et al. (2008) prepared two types of pellets containing vinpocetine (model insoluble drug) where Type I pellets contained a self-emulsifying system internally and an inert matrix externally, whereas Type II contained an inert matrix internally and a self-emulsifying system externally. Formulations were prepared in two steps. In the first step, the oil-surfactant mixture was added to water to form self-emulsifying systems whereas in the next stage this mixture was loaded onto MCC and lactose to form extrusion-spheronization mass for pellets. Results indicated that Type I pellets released $90 \%$ of vinpocetine within 30 min while the same quantity was released within $20 \mathrm{~min}$ from Type II pellets. The physical mixture of the excipients with drug was able to release around $25 \%$ of the drug in 60 $\mathrm{min}$. Although both types of pellets demonstrated adequate morphological and technological characteristics, type II pellets showed better drug solubility and in vivo bioavailability. The above investigations suggest that a solid dosage form containing a self-emulsifying system is a promising approach for the formulation of drug compounds with poor aqueous solubility. 


\section{Self-emulsifying beads (SE beads)}

Self-emulsifying beads can be formulated as a solid dosage form using smaller amounts of different excipients. Patil and Paradkar formulated an isotropic formulation of loratadine consisting of Captex 200, Cremophore EL and Capmul MCM. The SE mixture was loaded onto poly propylene beads (PPB) using the solvent evaporation method. Formulations were optimized for loading efficiency and in vitro drug release by evaluating their geometrical features such as bead size and pore architecture. Results indicated that the poly propylene beads are potential carriers for solidification of SE mixture, with sufficiently high SE mixture to PPB ratios for the solid form. The results indicated that selfemulsifying beads can be formulated as a solid dosage form with a minimal amount of solidifying agents.

\section{Self-emulsifying sustained-release microspheres}

You et al. (2006) prepared solid SE sustained-release microspheres of zedoary turmeric oil (oil phase) using the quasi-emulsion-solvent-diffusion method involving spherical crystallization. The release behaviour of zedoary turmeric oil from the formulation was found to be dependent upon the hydroxyl propyl methylcellulose acetate succinate to Aerosil 200 ratio. The plasma concentration time profiles after oral administration in rabbits showed a bioavailability of $135.6 \%$ compared with the conventional liquid SEFs.

\section{Self-emulsifying implants (SE implants)}

Research into SE implants has greatly increased the use and application of solid self-emulsifying formulation (S-SEF). Carmustine (BCNU) is a chemotherapeutic agent used to treat malignant brain tumours. However, its effectiveness is hindered by its short half life. In order to enhance its stability, the SEF of carmustine was formulated using tributyrin, Cremophor RH 40 (polyoxyl 40 hydrogenated castor oil) and Labrafil 1944 (polyglycolyzed glyceride). The self-emulsified BCNU was fabricated into wafers with a flat and smooth surface by compression moulding. The release profile was compared with a wafer implant fabricated using poly (d, 1-lactide-co-glycolide) acetic acid. It was found that SEF increased the in vitro half-life of BCNU to $130 \mathrm{~min}$ compared with 45 min with intact $\mathrm{BCNU}$. The in vitro release of BCNU from self-emulsifying PLGA wafers was prolonged up to 7 days and was found to have higher in vitro anti-tumor activity (Chae et al., 2005).

\section{Self-microemulsifying formulations}

Self-micro emulsifying formulations (SMEFs) have attracted great attention recently. In an attempt to combine the advantages of SMEFs with those of solid dosage forms and overcome the shortcomings of liquid formulations, increasing attention has been focused on solid self-(micro) emulsifying formulations. The thermotropic stability of SMEFs and their high drug loading efficiency make them a promising system for low aqueous soluble drugs (Jannin et al., 2007). SMEFs are usually placed in soft gelatin capsules, but can also be transformed into granules, pellets, powders for dry filled capsules or tablet preparations (Nazzal, Khan, 2006; Serratoni, Newton, 2007; Abdalla et al., 2008; Tan et al., 2009). The commercial success of the SMEF, Neoral ${ }^{\circledR}$ drew greater attention to the development of SMEFs. Many poorly water-soluble drugs such as acyclovir, atorvastatin, and fenofibrate have been reported to offer improved oral bioavailability by SMEFs (Wang et al., 2006; Shen, Zhong, 2006; Patel, Vavia, 2007).

Postolache et al. (2002) compared the bioavailability of two cyclosporine capsule products with different pharmaceutical formulations. Results showed that the test cyclosporine non-SMEFs formulation was not bioequivalent to the cyclosporine SMEFs formulation due to a statistically significantly lower absorption rate. These authors demonstrated that the non-self microemulsifying capsules are not totally interchangeable with the self microemulsifying capsules unless validated clinical and laboratory conversion protocols for each kind of organ transplantation are enforced.

Catarzi et al. (2008) reported the comparative impact of Transcutol and Neusilin ${ }^{\circledR}$ US2 on SMEFs. Results showed that the Neusilin- formulation resulted in hard tablets with a low tablet weight. However, Neusilin ${ }^{\circledR}$ tablets had similar disintegration times compare to Aeroperl ${ }^{\circledR}$ (Evonik Degussa). The dissolution profile obtained from the tablets showed improved profile when compared to Glyburide alone. Zvonar et al. (2010) suggested that, SMEFs possessing a composition similar to microcapsules with $\mathrm{Ca}$-pectinate shell and a drug loaded SMEFs as the core phase, would be a potential approach for enhancing low permeability and solubility of BCS class II drugs.

\section{Self nanoemulsifying formulations (SNEFs)}

The classical lipid nanoparticles that have been proposed for drug delivery are composed of solid lipids. A distinct advantage of SNEFs over polymeric nanoparticles is that the lipid matrix is made from physiologically tolerated lipid components, which decreases potential acute and chronic toxicity. 
Nazzal et al. (2002) developed a SNEF based on the eutectic properties of ubiquinone (CoQ10) and also studied the progress of emulsion formation and drug release mechanisms by turbidimetry and droplet size analysis. Results obtained from study revealed that eutectic-based semisolid SEFs can overcome the drawbacks of the traditional emulsified systems such as low solubility and irreversible precipitation of the active drug in the vehicle with time.

Cyclosporine lipid nanoparticles (lipospheres) consisting of phospholipids, Span 80, Tween 80, Tricaprin, and Cremophor RH 40 were prepared (Bekerman et al., 2004). The CsA dispersion systems prepared had a particle size ranging from $25 \mathrm{~nm}$ to $400 \mathrm{~nm}$. Particles with a size of $25 \mathrm{~nm}$ showed maximum oral bioavailability.

In a study by Nepal et al.(2010), the surfactant-cosurfactant blend (Witepsol ${ }^{\circledR} \mathrm{H} 35$ and Solutol ${ }^{\circledR}$ HS15) at a ratio of 1:4 led to sufficient reduction in free energy of the system to resist thermodynamic instability of the nanoemulsion as well as providing a sufficient mechanical barrier to coalescence oil droplets.

Koynova et al. (2010) suggested the use of nanosized self-emulsifying lipid vesicles as carriers for the inclusion of lipophilic dietary supplements. These were proposed as good alternatives to liposomal preparations which pose problems in stability, sterilization, and nonreproducibility between batches.

\section{Supersaturable self-emulsifying formulation}

Supersaturation represents a potent technique for enhancing absorption by generating and maintaining a supersaturated state in the intestine. Such formulations contain both a reduced amount of surfactant(s) and a polymeric precipitation inhibitor (e.g., water-soluble cellulosic polymers, such as HPMC). These maintain a su-

TABLE II - List of selected commercially available lipid-based formulations for oral administration

\begin{tabular}{|c|c|c|c|}
\hline Active moiety & $\begin{array}{l}\text { Trade name/ } \\
\text { Company }\end{array}$ & Dosage forms & Indication \\
\hline \multirow[t]{4}{*}{ Cyclosporin A } & $\begin{array}{c}\text { Neoral } \\
\text { (Novartis) }\end{array}$ & $\begin{array}{l}\text { Soft gelatin capsule, } \\
50 \text { and } 100 \mathrm{mg}\end{array}$ & Immuno-suppressant \\
\hline & $\begin{array}{l}\text { Sandimmune } \\
\text { (Novartis) }\end{array}$ & $\begin{array}{l}\text { Soft gelatin capsule, } 25, \\
50 \text { and } 100 \mathrm{mg}\end{array}$ & \\
\hline & Gengraf (Abbott) & Hard gelatin capsule & \\
\hline & $\begin{array}{l}\text { Panimumbioral } \\
\text { (Panacea Biotec) }\end{array}$ & $\begin{array}{l}\text { Capsule, } 50 \text { and } \\
100 \mathrm{mg}\end{array}$ & \\
\hline Ritonavir & $\begin{array}{l}\text { Norvir } \\
\text { (Abbott) }\end{array}$ & $\begin{array}{l}\text { Soft gelatin capsule, } \\
50 \text { and } 100 \mathrm{mg}\end{array}$ & HIV antiviral \\
\hline Isotretinoin & $\begin{array}{l}\text { Accutane } \\
\text { (Roche) }\end{array}$ & $\begin{array}{l}\text { Soft gelatin capsule, } 10, \\
20 \text { and } 40 \mathrm{mg}\end{array}$ & $\begin{array}{c}\text { Acute promyelocytic } \\
\text { leukemia }\end{array}$ \\
\hline Sanquinavir & $\begin{array}{c}\text { Fortovase } \\
\text { (Roche) }\end{array}$ & $\begin{array}{l}\text { Soft gelatin capsule, } \\
200 \mathrm{mg}\end{array}$ & HIV antiviral \\
\hline $\begin{array}{l}\text { Lopinavir and } \\
\text { Ritonavir }\end{array}$ & $\begin{array}{c}\text { Kaletra } \\
\text { (Abbott) }\end{array}$ & $\begin{array}{c}\text { Soft gelatin capsule, } 133.33 \mathrm{mg} \text { and } \\
\text { Ritonavir } 33.3 \mathrm{mg}\end{array}$ & HIV-1 antiviral \\
\hline Tipranavir & $\begin{array}{c}\text { Aptivus } \\
\text { (Boehringer Ingelheim) }\end{array}$ & $\begin{array}{l}\text { Soft gelatin capsule, } \\
250 \mathrm{mg}\end{array}$ & $\begin{array}{l}\text { HIV-1 } \\
\text { Antiviral }\end{array}$ \\
\hline Amprenavir & $\begin{array}{c}\text { Agenerase } \\
\text { (Glaxo Smithkline) }\end{array}$ & $\begin{array}{l}\text { Soft gelatin capsule, } \\
50 \mathrm{mg}\end{array}$ & HIV antiviral \\
\hline Valproic acid & $\begin{array}{l}\text { Convulex } \\
\text { (Pharmacia) }\end{array}$ & $\begin{array}{l}\text { Soft gelatin capsule, } \\
150,300,500 \mathrm{mg}\end{array}$ & Antiepileptic \\
\hline Bexarotene & $\begin{array}{l}\text { Targretin } \\
\text { (Ligand) }\end{array}$ & $\begin{array}{l}\text { Soft gelatin capsule, } \\
75 \mathrm{mg}\end{array}$ & Antineoplastic \\
\hline Calcitriol & $\begin{array}{l}\text { Rocaltrol } \\
\text { (Roche) }\end{array}$ & $\begin{array}{l}\text { Soft gelatin capsule, } \\
0.25,0.50 \mathrm{mcg}\end{array}$ & Calcium regulator \\
\hline Tretinoin & $\begin{array}{l}\text { Vesanoid } \\
\text { (Roche) }\end{array}$ & $\begin{array}{l}\text { Soft gelatin capsule, } \\
\qquad 10 \mathrm{mg}\end{array}$ & $\begin{array}{c}\text { Acute promyelocytic } \\
\text { leukemia }\end{array}$ \\
\hline
\end{tabular}


persaturated state of the drug in the body. As the literature suggested, directly supersaturating a system with a drug during manufacture adds to the risk of recrystallization of the product. Various ways of inhibiting recrystallization have been identified. Thermodynamic "freezing" inside a polymer is one such option. Under storage conditions, the drug is mobilized by thermodynamic changes in the polymeric structure. To avoid risk of direct supersaturation, several strategies can be employed, for example:

- Evaporation of a solvent from the system

- Activation of thermodynamically "frozen" drugsupersaturated islands by hydration.

However, attaining full knowledge of these processes, especially in a multi- component formulation, requires extensive research. Recently, Gao et al. (2008) investigated the mechanism responsible for the enhanced intestinal absorption of hydrophobic drugs from supersaturable SEFs containing HPMC. This effect could be attributed to enhanced permeation of drug to the enterocyte brush border region through the aqueous pathway by mimicking, or equilibrating with, the bile acid /bile acid mixed micelle pathway.

\section{MARKETED FORMULATIONS}

The successful commercialization of oral lipid- and surfactant-based formulations of poorly soluble drugs in the market has encouraged researchers to explore the field further. Sandimmune ${ }^{\circledR}$, Sandimmune Neoral ${ }^{\circledR}$, Norvir ${ }^{\circledR}$ (ritonavir), and Fortovase ${ }^{\circledR}$ (saquinavir) have been formulated as SEFs. The Sandimmune ${ }^{\circledR}$ and Sandimmune Neoral ${ }^{\circledR}$ formulations of CsA are perhaps the best known examples of marketed lipid and surfactant based systems and the pharmacokinetic has been studied and reviewed extensively (Ritschel, 1996). When diluted with water, these form a polydispersed oil-in-water macro/microemulsion.

Another formulation marketed as an amorphous, semi-solid dispersion was the hard gelatin capsule of ritonavir $\left(\right.$ Norvir $\left.^{\circledR}\right)$. However, unexpected precipitation of amorphous ritonavir as a less soluble crystalline form in the excipient matrix negatively impacted both the drug dissolution rate and bioavailability, leading to a temporary withdrawal of the product from the market in 1998. Norvir ${ }^{\circledR}$ was reintroduced in 1999 after reformulation as a thermodynamically stable solution containing $100 \mathrm{mg}$ of ritonavir solubilized in a self-emulsifying excipient delivered in soft gelatin capsules.

Saquinavir was first introduced in 1996 as a solid oral dosage form (Invirase ${ }^{\circledR}$ ) and subsequently, as a selfemulsifying lipid-based formulation in a soft gelatin capsule (Fortovase ${ }^{\circledR}$ ) containing $200 \mathrm{mg}$ of saquinavir. In
2006, Fortovase ${ }^{\circledR}$ was removed from the market due to lack of demand. Saquinavir is still available as $200 \mathrm{mg}$ and 500 mg Invirase hard gelatin capsules. Table II lists selected commercially available self-emulsifying formulations along with their characteristics.

\section{CONCLUSION}

The vast majority of new chemical entities and many existing drug molecules are poorly soluble. The oral delivery of poorly soluble drugs from solid oral dosage form continues to encounter significant formulation obstacles, such as decreased bioavailability, increased chances of food effects, incomplete release and high inter-patient variability. Oral SETs are a promising formulation approach to overcome these problems of poorly water soluble drugs. Advanced systems of this type include self nanoemulsifying (SNEFs) and microemulsifying (SMEFs) formulation systems which offer even greater advantages in drug delivery owing to the particle size of the dispersed phase. Self-emulsifying formulations can be converted to solid oral dosage forms such as granules, pellets and tablets with no effects, or only moderate effects, on the in vivo behavior of the systems. This characteristic of selfemulsifying systems is advantageous to formulators and is also convenient for patients.

\section{LIST OF ABBREVIATIONS}

$\begin{array}{ll}\text { AUC } & \text { Area Under Curve } \\ \text { API } & \text { Active pharmaceutical ingredient } \\ \text { BCNU } & \text { 1,3-bis (2-chloro ethyl)-1-nitrosourea } \\ \text { BCS } & \text { Biopharmaceutical classification system } \\ \text { C }_{\text {max }} & \text { Peak Plasma Concentration } \\ \text { CoQ 10 } & \text { Coenzyme Q 10 } \\ \text { CsA } & \text { Cyclosporine A } \\ \text { GI } & \text { Gastrointestinal } \\ \text { HIV } & \text { Human immuno deficiency virus } \\ \text { HLB } & \text { Hydrophilic Lipophilic balance } \\ \text { HPMC } & \text { Hydroxy propyl methyl cellulose } \\ \text { MCC } & \text { Micro Crystalline cellulose } \\ \text { NTD } & \text { Nitrendipine } \\ \text { PEG } & \text { Polyethylene Glycol } \\ \text { PGG } & \text { Polyglycolyzed glycerides } \\ \text { PLGA } & \text { Poly (d,1-lactide-co-glycolide) } \\ \text { PPB } & \text { Poly Propylene beads } \\ \text { SE } & \text { Self Emulsifying } \\ \text { SEFs } & \text { Self Emulsifying formulations } \\ \text { SETS } & \text { Self Emulsifying therapeutic systems } \\ \text { SMEDDS } & \text { Self Microemulsifying drug delivery system } \\ \text { SMEFs } & \text { Self-Micro emulsifying formulations }\end{array}$




$\begin{array}{ll}\text { SNEFs } & \text { Self nanoemulsifying Formulations } \\ \text { S-SEDDS } & \text { Solid self-emulsifying drug delivery system } \\ \text { S-SEFs } & \text { Super Saturable Self emulsifying formulations } \\ \text { Tmax } & \text { Time to reach peak plasma concentration } \\ \text { TPGS } & \begin{array}{l}\text { d-alpha tocopheryl polyethylene glycol 1000 } \\ \text { succinate }\end{array} \\ \text { ZTO } & \text { Zedoary Turmeric Oil }\end{array}$

NSAID Nonsteroidal anti-inflammatory Drug

\section{REFERENCES}

ABDAllA, A.; KLEIN, S.; MADER, K. A new selfemulsifying drug delivery system for poorly soluble drugs: characterization, dissolution, in vitro digestion and incorporation into solid pellets. Eur. J. Pharm. Sci., v.35, p.457-464, 2008.

ABDALLA, A.; MADER, K. Preparation and characterization of a self-emulsifying pellet formulation. Eur. J. Pharm. Sci., v.66, p.220-226, 2007.

ALSENZ, J.; KANSY, M. High throughput solubility measurement in drug discovery anddevelopment. Adv. Drug Dev. Rev., v.59, p.546-567, 2007.

ANTRON, N.; VANDAMME, T.F. The universality of low energy nano emulsification. Int. J. Pharm., v.377, p.142147, 2009.

ARIDA, A.I.; MOAWIA, M.A.; HANTASH, A.J.H.A.I.A.; MOAWIA, M.A.; HANTASH, A.J.H. Improving the high variable bioavailability of griseofulvin by SEFs. Chem. Pharm. Bull., v.55, p.1713-1719, 2007.

ATTAMA, A.A. The use of solid self-emulsifying systems in the delivery of diclofenac. Int. J. Pharm., v.262, p.23-28, 2003.

BALAKRISHNAN, P.; LEE, B.J.; LEE, Y.I.; WOO, J.S.; YONG, C.S.; CHOI, H.G. Enhanced oral bioavailability of coenzyme Q10 by self-emulsifying drug delivery systems. Int. J. Pharm., v.374, p.66-72, 2009.

BEKERMAN, T.; GOLENSER J.; DOMB, A. Cyclosporine nano particulate lipospheres for oral administration. $J$. Pharm. Sci., v.93, p.1264-1270, 2004.

BENET, L.Z.; AMIDON, G.L.; BARENDS, D.M.; LENNERN, A.H.; POLLI, J.E.; SHAH, V.P.; STAVCHANSKY, S.A.; YU, L.X. The use of BDDCS in classifying the permeability of marketed drugs. Pharm. Res., v.25, p.483-488, 2008.
BITTNER, B.; MOUNTFIELD, B. Intravenous administration of poorly water soluble new drug entities in early discovery: the potential impact of formulation on pharmacokinetic parameters. Curr. Opin. Drug Dev., v.5, p.59-71, 2002.

BREITENBACH, J. Melt extrusion: from process to drug delivery technology. Eur. J. Pharm. Biopharm., v.54, p.107$117,2002$.

CHAE, G.S.; LEE, J.S.; KIM, S.H. Enhancement of the stability of BCNU using self-emulsifying drug delivery systems (SEDDS) and in vitro antitumor activity of self-emulsified BCNU-loaded PLGA wafer. Int. J. Pharm., v.301, p.6-14, 2005.

CHARMAN, S.A.; CHARMAN, W.N.; ROGGE, M.C.; WILSON, T.D.; DUTKO, F.J.; POUTON, C.W. Selfemulsifying drug delivery systems: formulation and biopharmaceutic evaluation of an investigational lipophilic compound. Pharm. Res., v.9, p.87-93, 1992.

CHARMAN, W.N.; STELLA, V.J. Transport of lipophilic molecules by the intestinal lymphatic system. Adv. Drug Deliv. Rev., v.7, p.1-14, 1991.

CHONG-KOOK, K.; PARK, J.S. Solubility enhancers for oral drug delivery. Am. J. Drug Deliv., v.2, p.113-130, 2004.

CONSTANTINIDES, P.P. Lipid microemulsions for improving drug dissolution and oral absorption: physical and biopharmaceutical aspects. Pharm. Res., v.12, p.15611572, 1995.

CONSTANTINIDES, P.P.; TUSTIAN, A.; KESSLER, D.R. Tocols emulsions for drug solubilization and parentral delivery. Adv. Drug Deliv. Rev., v.56, p.1243-1255, 2004.

CUI, J.; YU, B.; ZHAO, Y.; ZHU,W.; LI, H.; LOU, H.; ZHAI, G. Enhancement of oral absorption of curcumin by selfmicroemulsifying drug delivery systems. Int. J. Pharm., v.371, p.148-155, 2009.

DATE, A.A.; NAGARSENKER, M.S. Design and evaluation of self nanoemulsifying drug delivery system (snedds) for cefpodoxime proxetil. Int. J. Pharm. v.329, p.166-172, 2007.

DAVIS, M.E.; BREWSTER, M.E. Cyclodextrin-based pharmaceutics: past, present and future. Nat. Rev. Drug Dis., v.3, p.1023-1035, 2004. 
DIXIT, R.P.; NAGARSENKER, M.S. Formulation and in vivo evaluation of self-nano emulsifying granules for oral drug delivery of a combination of ezetimibe and simvastatin. Drug Dev. Ind. Pharm., v.34, p.1285-1296, 2008.

DRESSMAN, J.; BUTLER, J.; HEMPENSTALL, J.; REPPAS, C. The BCS: Where do we go from here? Pharm. Technol., v.25, p.68-77, 2001.

FAHR, A.; LIU, X. Drug delivery strategies for poorly-water soluble drugs. Expert Opin. Drug Del., v.4, p.403-416, 2007.

FENSKE, D.B.; CHONN, A.; CULLIS, P.R. Liposomal nanomedicine: an emerging field. Toxicol. Pathol., v.36, p.21-29, 2008.

FERNANDEZ, S.; CHEVRIER, S.; RITTER, N.; MAHLER, B.; DEMARNE, F.; CARRIÈRE, F.; JANNIN, V. In vitro gastrointestinal lipolysis of four formulations of piroxicam and cinnarizine with the self-emulsifying excipients Labrasol ${ }^{\circledR}$ and Gelucire®. Pharm. Res., v.26, p.1901-1910, 2009.

FRANCESCHINIS, E.; BORTOLETTO, C.; PERISSUTTI, B.; ZOTTO, M.D.; VOINOVICH, D. Self-emulsifying pellets in a lab-scale high shear mixer: Formulation and production design. Powder Technol., v.207, p.113-118, 2011.

FRANCESCHINIS, E.; VOINOVICH, D.; GRASSI, M.; PERISSUTTI FILIPOVIC-GRCIC, B.J.; MARTINAC, A.; MERIANI-MERLO, F. Self-emulsifying pellets prepared by wet granulation in high-shear mixer: influence of formulation variables and preliminary study on the in vitro absorption. Int. J. Pharm., v.291, p.87-97, 2005.

FUJI CHEMICAL INDUSTRY CO. LTD. Japan. Benefits of using the right carrier for solid dispersion systems. Available at: $<$ http//:www.in-pharmatechnologist.com/Productinnovations/(filter)/Product-Brochures. p.1-3>. Accessed on:12 jan. 2009.

GAO, L.; ZHANG, D.; CHEN, M. Drug nanocrystals for the formulation of poorly soluble drugs and its application as a potential drug delivery system. J. Nanopart. Res., v.10, p.845-846, 2008.

GAO, P.; MOROZOWICH, W. Development of supersaturatable self-emulsifying drug delivery system formulations for improving the oral absorption of poorly soluble drugs. Expert. Opin. Drug. Discov., v.3, p.97-110, 2006.
GEORGAKOPOULOS, E.; FARAH, N.; VERGNAULT, G. Oral anhydrous non-ionic microemulsions administered in softgel capsules. B. T. Gattefosse. v.85, p.11-20, 1992.

GERSHANIK, T.; BENITA, S. Self-dispersing lipid formulations for improving oral absorption of lipophilic drugs. Eur. J. Pharm. Biopharm., v.50, p.179-188, 2000.

GIBSON, L. Lipid-based excipients for oral drug delivery, in: D.J. Hauss (Ed.), Oral lipid-based formulations: enhancing the bioavailability of poorly water-soluble drugs, Informa Healthcare, Inc., New York, p. 43-51, 2007.

GILIYAR, C.; FICKSTAD, D.T.; TYAVANAGIMATT, S. Challenges and opportunities in oral delivery of poorlywater soluble drugs. Drug Del. Technol., v.6, p.57-63, 2006.

GROVES, M.J.; MUSTAFA, R.M.A.; CARLESS, J.E. Phase studies of mixed phosphate surfactants, $n$-hexane and water. J. Pharm. Pharmacol., v.26, p.616-623, 1974.

GULLAPALLI, R.P. Soft gelatin capsules (softgels), J. Pharm. Sci., v.99, p.4107-4148, 2010.

GURSOY, R.N.; BENITA, S. Self-emulsifying drug delivery systems (SEDDS) for improved oral delivery of lipophilic drugs. Biomed. Pharmacother, v.58, p.173-182, 2004.

HAMDANI, J.; MOËS, A. J.; AMIGHI, K. Physical and thermal characterisation of Precirol ${ }^{\circledR}$ and $\mathrm{Compritol}^{\circledR}$ as lipophilic glycerides used for the preparation of controlled-release matrix pellets. Int. J. Pharm., v.260, p.47-57, 2003.

HAUSS, D.J. Oral lipid-based formulations. Adv. Drug. Deliv. Rev., v.59, 667-676, 2007.

HAUSS, D.J.; FOGAL, S.E.; FICORILLI, J.V.; PRICE, C.A.; ROY, T.; JAYARAJ, A.A.; KEIRNS, J.J. Lipid based delivery systems for improving the bioavailability and lymphatic transport of a poorly water soluble LTB4 inhibitor. J. Pharm. Sci., v.87, p.164-169, 1998.

HOLM, R.; PORTER, C.J.H.; MÜLLERTZ,A.; KRISTENSEN, H.G.; CHARMAN, W.N. Structured triglyceride vehicles for oral delivery of halofantrine: examination of intestinal lymphatic transport and bioavailability in conscious rats. Pharm. Res., v.19, p.1354-1361, 2002.

HUMBERSTONE, A.J.; CHARMAN, W.N. Lipid based vehicles for oral delivery of poorly water soluble drugs. Adv. Drug Del. Rev., v.25, p.103-128, 1997. 
IOSIO, T.; VOINOVICH, D; GRASSI, M.; PINTO, J.F.; PERISSUTTI, B.; ZACCHIGNA, M.; QUINTAVALLE, U.; SERDOZ, F. Bi-layered self-emulsifying pellets prepared by co-extrusion and spheronization: Influence of formulation variables and preliminary study on the in vivo absorption. Eur. J. Pharm. Biopharm., v.69, p.686-697, 2008.

IOSIO, T.; VOINOVICHA, D.; PERISSUTTI, B.; SERDOZA, F.; HASAA, D.; GRABNARB, I.; DALL'ACQUAC, S.; ZARAD, G.P. Oral bioavailability of silymarin phytocomplex formulated as self-emulsifying pellets. Phytomedicine, v.18, p.505-512, 2011.

JANNIN, V.; MUSAKHANIAN, J.; MARCHAUD, D. Approaches for the development of solid and semi-solid lipid-based formulations. Adv. Drug Del. Rev., v.60, p.734746, 2007.

JULIANTO, T.; YUEN, K.H.; NOOR, A.M. Improved bioavailability of vitamin E with a self-emulsifying formulation. Int. J. Pharm., v. 200, p.53-57, 2000.

KANG, B.K.; LEE, J.S.; CHON, S.K.; JEONG, S.Y.; YUK, S.H.; KHANG, G.; LEE, H.B.; CHO, S.H. Development of self-microemulsifying drug delivery systems (SMEDDS) for oral bioavailability enhancement of simvastatin in beagle dogs. Int. J. Pharm., v.274, p.65-73, 2004.

KARIM, A.; GOKHALE, R.; COLE, M.; SHERMAN, J.; YERAMIAN, P.; BRYANT, M.; FRANKE, H. HIV protease inhibitor SC-52151: a novel method of optimizing bioavailability profile via a microemulsion drug delivery system. Pharm Res., v.11, p.S368, 1994.

KAWAKAMI, K.; YOSHIKAWA, T.; MOROTO. Y. Microemulsion formulation for enhanced absorption of poorly soluble drugs: I. prescription design. J. Control. Release, v.81, p.75-82, 2002.

KECK, C.M.; MULLER, R.H. Drug nanocrystals of poorly soluble drugs produced by high pressure homogenization. Eur. J. Pharm. Biopharm., v.62, p.3-16, 2006.

KHOO, S.M.; PORTER, C.J.; EDWARDS, G.A.; CHARMAN, W.N. Intestinal lymphatic transport is the primary route for halofantrine after oral postprandial administration. Pharm. Sci., v.1, p.614-624,1999.
KOYNOVA, R.; MARIANA, T. Nanosized self-emulsifying lipid vesicles of diacylglycerol-PEG lipid conjugates: Biophysical characterization and inclusion of lipophilic dietary supplements. Biochim. Biophys. Acta., v.1798, p.646-653, 2010.

KRISHNAIAH, Y.S.R. Pharmaceutical technologies for enhancing oral bioavailability of poorly soluble drugs. $J$. Bioequiv. Bioavail., v.2, p.28-36, 2010.

LEUNER, C.; DRESSMAN, J. Improving drug solubility for oral delivery using solid dispersions. Eur. J. Pharm. Biopharm., v.50, p. 47-60, 2004.

LI, P.; ZHAO, L. Developing early formulations: practice and perspective. Int. J. Pharm., v.341, p.1-19, 2007.

LIPINSKI, C.A. Avoiding investment in doomed drugs: is poor solubility an industry wide problem? Curr. Drug Discov., v.4, p.17-19, 2001.

LIPINSKI, C.A. Poor aqueous solubility: an industry wide problem in drug discovery. Am. Pharm. Review., v.5, p.82$85,2002$.

LIVERSIDGE, G.; CUNDY, K. Particle size reduction for the improvement of oral bioavailability of hydrophobic drugs: I. absolute oral bioavailability of nanocrystallinedanazol in beagle dogs. Int. J. Pharm., v.17, p.91-97, 1995.

MALAM, Y.; YOGESH, K.; LOIZIDOU, M.; SEIFALIAN, A. Liposomes and nanoparticles: nanosized vehicles for drug delivery in cancer. Trends Pharmacol. Sci., v.30, p.592$599,2009$.

MERISKO-LIVERSIDGE, E.; LIVERSIDGE, G.G.; COOPER, E.R. Nanosizing: a formulation approach for poorly-watersoluble compounds. Eur. J. Pharm. Sci., v.18, p.113-120, 2003.

MOHANTY, C.; ACHARYA, S.; SAHOO, S.; SANJEEB. K. Micelles: the multifunctional nanocarrierfor colloidal drug delivery. In: FANUN, M. (Ed.). Colloids in drug delivery. Boca Raton: Taylor and Francis, Inc., 2010. v.148, p.157-175.

MORAIS, J.M.; SANTOS, O.; DELICATO, T.;DA ROCHA FILHO, P. Characterization and evaluation of electrolyte influence on canola oil/ water nanoemulsion. J. Dispersion Sci. Technol., v.27, p.1009-1014, 2006. 
MULLER, R.H. Nanosuspensions as Particulate drug formulations in therapy: Rationale for development and what we can expect in the future. Adv. Drug Deliv. Rev., v.47, p.3-19, 2001.

NAZZAL, S.; KHAN, M.A. Controlled release of a selfemulsifying formulation from a tablet dosage form: Stability assessment and optimization of some processing parameters. Int. J. Pharm., v.315, p.110-121, 2006.

NAZZAL, S.; SMALYUKH, I.I.; LAVRENTOVICH, O.D.;KHAN, M.A. Preparation and in vitro characterization of a eutectic based semisolid self-nanoemulsified drug delivery system (SNEDDS) of Ubiquinone: mechanism and progress of emulsion formation. Int. J. Pharm., v.235, p.247-265, 2002.

NEPAL, P.R.; HAN, H.K.; CHOI, H.K. Preparation and in vitro-in vivo evaluation of Witepsol ${ }^{\circledR}$ H35 based selfnanoemulsifying drug delivery systems (SNEDDS) of coenzyme Q10. Eur. J. Pharm. Sci., v.39, p.224-232, 2010.

NEWTON, J.M.; PINTO, M.R.; PODCZECK, F. The preparation of pellets containing a surfactant or a mixture of mono- and di-glycerides by extrusion/spheronization. Eur. J. Pharm. Sci., v.30, p.333-342, 2007.

NIELSEN, F.S.; GIBAULT E, L.W. Characterization of prototype self-nanoemulsifying formulations of lipophilic compounds. J. Pharm. Sci., v.96, p.876-892, 2007.

ODEBERG, J.M.; KAUFMANN, P.; KROON, K.G.; HOGLUND, P. Lipid drug delivery and rational formulation design for lipophilic drugs with low oral bioavailability, applied to cyclosporine. Eur. J. Pharm. Sci., v.20, p.375382, 2003.

OVERHOFF, K.A.; ENGSTROM, J.D.; CHEN, B.; SCHERZER, B.D.; MILNER, T.E.; JOHNSTON, K.P.; WILLIAMS R.O.III, Novel ultra-rapid freezing particle engineering process for enhancement of dissolution rates of poorly-water soluble drugs. Eur. J. Pharm. Biopharm., v.65, p.57-67, 2007.

PATEL, A.R.; VAVIA, P.R.; Preparation and in vivo evaluation of SMEDDS (self microemulsifying drug delivery system) containing fenofibrate. AAPS J., v.9, p.E344-E352, 2007.

PATHAK, P.; MEZIANI, M.J.; SUN, Y.P. Supercritical fluid technology for enhanced drug delivery. Expert Opin. Drug Deliv., v.2, p.747-761, 2005.
PATIL, P. Effect of formulation variables on preparation and evaluation of gelled self-emulsifying drug delivery system (SEDDS) of ketoprofen. AAPS Pharm. Sci. Tech., v.5, p.34-42, 2004.

PATIL, P.; PARADKAR, A. Porous polystyrene beads as carriers for self-emulsifying system containing loratadine. AAPS Pharm. Sci. Tech., v.7, p.E1-E7, 2006.

POSTOLACHE, P.; PETRESCU, O.; DORNEANU, V. Cyclosporine bioavailability of two physically different oral formulations. Eur. Rev. Med. Pharmacol. Sci., v.6, p.127-131, 2002.

POUTON, C.W. Formulation of self-emulsifying drug delivery systems. Adv. Drug Deliv. Rev., v.25, p.47-58, 1997.

POUTON, C.W. Lipid formulations for oral administration of drugs: non-emulsifying, selfemulsifying and selfmicroemulsifying drug delivery systems. Eur. J. Pharm., v.11, p.93-98, 2000.

PU, X.; SUN, J.; LI, M.; HE, Z. Formulation of nanosuspensions as a new approach for the delivery of poorly soluble drugs. Curr. Nanosci., v.5, p.417-427, 2009.

RANG, M.J.; MILLER, C.A.. Spontaneous emulsification of oils containing hydrocarbon, non-ionic surfactant, and oleyl alcohol. J. Colloids Interface Sci., v.209, p.179-192, 1999.

REISS, H. Entropy-induced dispersion of bulk liquids. $J$. Colloids Interface Sci., v.53, p.61-70, 1975.

RITSCHEL,W.A. Microemulsions for improved peptide absorption from the gastrointestinal tract. Methods Find Exp. Clin. Pharm., v.13, p.205-220,1996.

SCHWARZ, J. Solid self-emulsifying dosage form for improved delivery of poorly soluble hydrophobic compounds and the process of preparation thereof. US patent application 20030072798. April 17, 2003.

SERRATONI, M.; NEWTON, M. Controlled drug release from pellets containing water-insoluble drugs dissolved in a self-emulsifying system. Eur. J. Pharm. Biopharm., v.65, p.94-98, 2007.

SETHIA, S.; SQUILLANTE, E. Solid dispersions: revival with greater possibilities and applications in oral drug delivery. Crit. Rev. Ther. Drug Carrier Syst., v.20, p.215-247, 2003. 
SETTHACHEEWAKUL, S.; MAHATTANADUL, S.; PHADOONGSOMBUT, N.; PICHAYAKORN, W.; WIWATTANAPATAPEE, R. Development and evaluation of self-microemulsifying liquid and pellet formulations of curcumin, and absorption studies in rats. Eur. J. Pharm. Biopharm., v.76, p.475-485, 2010.

SHAH, N.H.; CARVAJAL, M.T.; PATEL, C.I.; INFELD, M.H.; MALICK, A.W. Self-emulsifying drug delivery systems (SEDDS) with polyglycolized glycerides for improving in vitro dissolution and oral absorption of lipophilic drugs. Int. J. Pharm., v.106, p.15-23, 1994.

SHEN, H.; ZHONG, M. Preparation and evaluation of selfmicroemulsifying drug delivery systems (SMEDDS) containing atorvastatin. J. Pharm. Pharmacol., v.58, p.1183-1191, 2006.

SINGH, A.K.; CHAURASIYA, A.; AWASTHI, A.; MISHRA, G.; ASATI, D. Oral bioavailability enhancement of exemestane from self-microemulsifying drug delivery system (SMEDDS). AAPS Pharm. Sci. Tech., v.10, p.906916, 2009

STEGEMANN, S.; LEVEILLER, F.; FRANCHI, D.; DEJONG, H.; LINDEN, H. When poor solubility becomes an issue: from early stage to proof of concept. Eur. J. Pharm. Sci., v.31, p.249-261, 2007.

STELlA, V.; QANREN, H. Cyclodextrins. Toxicol. Pathol., v.36, p.30-42, 2008.

TAN, A.; SIMOVIC, S.; DAVEY, A.K.; RADES, T.; PRESTIDGE, C.A. Silica-lipid hybrid (SLH) microcapsules: a novel oral delivery system for poorly soluble drugs. $J$. Control. Release., v.134, p.62-70, 2009.

TANG, B; CHENG, G; GU, G.C.; XU, C.H. Development of solid self-emulsifying drug delivery systems: preparation techniques and dosage forms. Drug Discov. Today, v.13, p.606-612, 2008.

TIMPE, C. Drug solubilisation strategies applying nanoparticulate formulation and solid dispersion approaches. Drug Dev. Pharm. Review., v.13.p.12-21, 2010.
TULEU, C. Comparative bioavailability study in dogs of a self-emulsifying formulation of progesterone presented in a pellet and liquid form compared with an aqueous suspension of progesterone. J. Pharm. Sci., v.93, p.1495-1502, 2004.

WAKERLY, M.G.; POUTON, C.W.; MEAKIN, B.J.; MORTON, F.S. Self emulsification of vegetable oil-non-ionic surfactant mixtures. ACS Symp. Ser., v.311, p.242-255, 1986.

WANG, L.; DONG, J.; EASTOC, J.; LI, X. Design and optimization of a new self-nano emulsifying drug delivery system. J. Colloid Interface Sci., v.330, p.443-448, 2009.

WANG, L.; CUI F.D.; SUNADA, H. Preparation and evaluation of solid dispersions of nitrendipine prepared with fine silica particles using the melt-mixing method. Chem. Pharm. Bull.,v.54, p.37-43, 2006.

WANG, Z.; SUN, J.; WANG, Y.; LIU, X.; LIU, Y.; FU, Q.; MENG, P.; HE, Z. Solid self-emulsifying nitrendipine pellets: preparation and in vitro/in vivo evaluation. Int. J. Pharm., v.383, p.1-6, 2010.

WOO, J.S.; SONG, Y.K.; HONG, J.Y.; LIMD, S.J.; KIM, C.K. Reduced food-effect and enhanced bioavailability of a selfmicroemulsifying formulation of itraconazole in healthy volunteers. Eur. J. Pharm. Sci., v.33, p.159-165, 2008.

YAO, G.; LI, Y. Preparation, characterization and evaluation of self-micro emulsifying drug delivery systems (SMEDDS) of Ligusticum chuanxiong oil. Biomed. Pharmacother. (in press), 2010.

YI T.; WAN J.; XU H.; YANG X.A new solid selfmicroemulsifying formulation prepared by spray-drying to improve the oral bioavailability of poorly water soluble drugs. Eur. J. Pharm. Biopharm.,70, p.439-444, 2008.

YOU, J. Study of the preparation of sustained-release microspheres containing zedoary turmeric oil by the emulsion-solvent-diffusion method and evaluation of the self-emulsification and bioavailability of the oil. Colloids Surf. B Biointerfaces, v.48, p.35-41, 2006.

ZVONAR, A.; BERGINC, K.; KRISTL, A.; GASPERLIN, M. Microencapsulation of self-microemulsifying system: Improving solubility and permeability of furosemide. Int. J. Pharm., v.388, p.151-158, 2010.

Received for publication on $27^{\text {th }}$ August 2010 Accepted for publication on $10^{\text {th }}$ May 2011 
